\title{
Effects of kefir on coccidial oocysts excretion and performance of dairy goat kids following weaning
}

\author{
Gürbüz Daș • Cengiz Atașoğlu • Hande Ișıl Akbağ • \\ Cemil Tölü • İsmail Yaman Yurtman • Türker Savaș
}

Accepted: 8 December 2011 / Published online: 23 December 2011

(C) The Author(s) 2011. This article is published with open access at Springerlink.com

\begin{abstract}
The aim of this study was to investigate effects of kefir, a traditional source of probiotic, on coccidial oocysts excretion and on the performance of dairy goat kids following weaning. Twin kids were randomly allocated to one of two groups at weaning. Kids of the first group received $20 \mathrm{ml}$ of kefir daily for 6 weeks (KEF), while kids in the control group were given a placebo (CON). Individual faecal samples were regularly ( $n=18$ per kid) taken to quantify the number of coccidial oocysts per gram of faeces $(\mathrm{OpG})$. There were no differences between the groups in terms of body weight development $(P>0.05)$ and feed consumption. Kids of both groups were not able to consume enough feed to meet their nutrient requirements during the first 3 weeks following weaning. KEF had a lower frequency of OpG positive samples than CON $(P=0.043)$. Kefir did not affect the maximum oocyst excretion and age of the kids at the highest oocyst excretion $(P>0.05)$. KEF shed numerically $35 \%$ lower coccidial oocysts than the controls, which corresponded to a statistical tendency $(P=0.074)$ in lowering Log-OpG in comparison to CON. While KEF had a lower frequency of $\mathrm{OpG}$ positive samples and tended to shed lower OPG by around one-third, the frequency of diarrhea, level of highest oocyst excretion, and performance of the kids remained unaffected. Therefore, it is concluded that overall effects of kefir do not have a significant
\end{abstract}

G. Daş • C. Ataşoğlu • H. I. Akbağ • C. Tölü • İ. Y. Yurtman •

T. Savaş

Department of Animal Science,

Çanakkale Onsekiz Mart University,

17020 Çanakkale, Turkey

G. Daș $(\bowtie)$

Department of Animal Science, University of Göttingen,

Abrecht-Thaer-Weg 3,

37075 Göttingen, Germany

e-mail: gdas@gwdg.de impact on sub-clinical infection and performance in weaned kids under relatively high-hygienic farming conditions.

Keywords Growth · Host nutrition · Parasite $\cdot$ Probiotic $\cdot$ Sub-clinical coccidiosis

\section{Introduction}

Coccidiosis, a parasitic infection caused by Eimeria species and which occurs particularly in young and stressed animals, is one of the economically most important constraints in sheep and goat production (Kusiluka et al. 1998). The clinical state of infection is often reported as one of the main factors responsible for kid mortality in the pre- and post-weaning periods (Koudela and Bokova 1998; Imik et al. 2000; Donkin and Boyazoglu 2004). As the clinical signs of the infection are not observed in the sub-clinical cases, the impact of subclinical coccidiosis on farm economy seems to have been neglected. There is evidence that natural sub-clinical infections with coccidia can impair growth performance of young ruminants (Alzieu et al. 1999; Gauly et al. 2004). Accordingly, high negative correlations between oocyst counts and body weight development have been reported in lambs during growth period (Gauly et al. 2004; Reeg et al. 2005). As summarized by Değer et al. (2003), prevalence of asymptomatic sub-clinical coccidial infections, confirmed with the presence of Eimerian oocysts in faeces of goats, ranges between $53.3 \%$ and $94.8 \%$ in Turkey, which is similar to the other reports from tropical and sub-tropical regions of the world (Jalila et al. 1998; Koudela and Bokova 1998; Harper and Penzhorn 1999; Wang et al. 2010; Zhao et al. 2011).

The classical control and treatment of the infection are mainly based on the use of anticoccidial drugs (Stafford et al. 
1994; Morand-Fehr et al. 2002). However, due to increasing resistance of parasites to the frequently used drugs, alternative approaches that do not rely on chemical drugs are becoming more important (Stear et al. 2007). In this context, probiotics may contribute to control strategies in sustainable animal production. Although there are successful attempts to use probiotics for controlling coccidiosis in broiler chickens (Dalloul et al. 2005), to date, there are no similar reports in goat kids. Kefir is made from fermented milk, and consumed as a beverage with probiotic activity (Otles and Cagindi 2003). Kefir stimulates proliferation and colonization rate of beneficial bacteria in the gut, which in turn prevents overgrowth of certain pathogens, particularly under weaning conditions (Ota 1999). Weaning is an inevitable husbandry practice that affects the gastrointestinal microbial ecosystem. Radical changes in the feeding habits of individuals are the most noticeable stressors caused by weaning (Orgeur et al. 1998). Thus the transition period from a non-ruminant to a ruminant is a critical period in which the digestion processes represent high vulnerability to gastrointestinal disturbances (Draksler et al. 2002).

We have previously observed that coccidial oocyst counts of naturally infected kids tend to increase following weaning (Daş et al. 2005). Eimeria spp. are intracellular parasites (Taylor et al. 2007), which must first adhere to epithelial surfaces in the gastrointestinal tract to invade host cells for establishing and further replicating. Gut-adapted probiotic bacteria may compete for adhesion sites and occupy common receptors on the epithelial cells (Dalloul et al. 2005). Therefore, we hypothesized that probiotic supplementation may contribute to the beneficial microorganism populations in the gastrointestinal tract and thereby decrease vulnerability to coccidiosis in weaned goat kids. The aim of this study was to investigate the effects of kefir on coccidial oocyst excretion and performance parameters of dairy goat kids following weaning.

\section{Material and methods}

Animals and treatment

The study was carried out with 20 twin Saanen kids, born within a period of 9 days, at the Technological and Agricultural Research Centre (TETAM) of Çanakkale Onsekiz Mart University, Turkey ( $38 \mathrm{~m}$ altitude, $40^{\circ} 7^{\prime} 38.82^{\prime \prime} \mathrm{N}, 26^{\circ} 26^{\prime} 24.66^{\prime \prime} \mathrm{E}$ ). In the pre-weaning period, all kids were kept together with their mothers as one group. The experiment was initiated immediately after weaning. Each of the weaned twin kids was allocated to one of two experimental groups $(n=10)$ with equal numbers of each gender. Kids of the first group received $20 \mathrm{ml}$ of kefir orally per day before morning feeding for 42 days (KEF), while the kids of the control group received a placebo with the same amount of water daily $(\mathrm{CON})$. Fresh kefir was obtained from a commercial company (Altınkılıç contained Lactococcus spp. $\left(10^{10}-10^{11} \mathrm{cfu} / \mathrm{g}\right)$, Lactobacillus spp. $\left(4.7 \times 10^{3} \mathrm{cfu} / \mathrm{g}\right)$ and yeasts $\left(10^{3} \mathrm{cfu} / \mathrm{g}\right)$. Concentration of microorganisms in kefir was approximately $1.7 \times 10^{11} \mathrm{cfu}$ per $\mathrm{kg}$ of the estimated final body weight $(12 \mathrm{~kg})$, which was higher than that given $\left(1.2 \times 10^{9} \mathrm{cfu} / \mathrm{kg}\right.$ body weight [BW]) in a previous study carried out with the same animal genetic material (Ataşoğlu et al. 2010).

Initial values of weaning weight and age of the kids were similar between the groups (one-way analysis of variance [ANOVA], $P>0.05$ ). Average weaning age and weight of the kids (means \pm SD) were 47.6 \pm 2.74 days (range 42-51 days) and $8.98 \pm 1.11 \mathrm{~kg}$, respectively. Following weaning, the groups of kids were housed in two growth units within the same experimental stable, separated with metal fence panels. Straw was used as litter material and removed weekly to ensure a general level of sanitation in the stable. Grower concentrate (880.4 g dry matter $[\mathrm{DM}] / \mathrm{kg} ; 198.5 \mathrm{~g}$ crude protein $[\mathrm{CP}] / \mathrm{kg}$ $\mathrm{DM})$ and alfalfa pellets (881.7 g DM/kg; $155.1 \mathrm{~g} \mathrm{CP} / \mathrm{kg} \mathrm{DM})$ were offered ad libitum under group conditions. Daily concentrate and alfalfa consumptions of the groups were recorded. Water was also offered ad libitum. The kids were weighed weekly using an electronic scale $( \pm 20 \mathrm{~g})$ and daily weight gains $(\mathrm{ADG})$ for each week were calculated.

\section{Faecal samples}

Faecal samples were taken from each kid three times per week for 6 weeks following weaning. As it was previously confirmed that the vast majority of animals kept in the research farm were positive for the presence of coccidia in their faeces, it was assumed that the kids included in this study would naturally acquire sporulated coccidial oocysts at early stages of life due to environmental contamination and would become sub-clinically infected. Individual faecal samples were collected directly from the rectum at the same time of sampling days. Faecal samples were examined by a modified McMaster counting technique with saturated $\mathrm{NaCl}$ as the flotation fluid (MAFF 1986). Number of oocysts per gram of faeces $(\mathrm{OpG})$, a quantitative measure of sub-clinical coccidiosis, was calculated and taken into consideration as total Eimeria oocysts count without species specification. Samples containing $\geq 100$ oocysts were considered positive for OpG. All samples were examined on the same sampling day without any delay. The kids were monitored daily by one person for the presence of diarrhea by checking the hindquarter of each kid for fresh watery faeces.

\section{Statistics}

A general linear model was used for analyzing BW and ADG data by performing repeated-measures ANOVA using Proc Mixed of SAS Institute Inc (2010). The model included fixed effects of treatment (CON and KEF), gender (female and 
male), week (1-6) and all possible interactions among these factors. Due to repeated measurements over the experimental weeks, effect of individual animal was included in the model as random. Descriptive statistics were calculated for feed consumption and estimated nutrient consumptions of the groups.

OpG counts were logarithmically transformed using a function $\left[\log _{10}(\mathrm{OpG}+1)\right]$ to correct for heterogeneity of variance and to produce an approximately normally distributed data set. Differences between oocyst counts of the groups (Log-OpG) were analyzed with repeated measures analysis of variance. In this model, treatment, gender, sampling day (1-18) as well as all possible interactions among these factors were included as fixed factors. As the faecal samples were taken from the same kids on different sampling days $(n=18)$, repeatedly sampled kid (subject) was included in the model as random.

Effects of kefir on the frequency of coccidia free faecal samples (OpG negative samples) and on the occurrence of diarrhea was assessed with a logistic regression using the Genmod procedure of SAS Institute Inc (2010).

\section{Results}

Changes in average daily total feed consumption of the groups are presented in Fig. 1. Feed consumption of the groups increased from the beginning to the end of the study with a more prominent increase observed during the last 3 weeks. Overall average daily feed (concentrate + alfalfa pellet) consumption of the kids were $524 \pm 67$ and $480 \pm 76 \mathrm{~g} /$ day for the CON and KEF groups, respectively.

Weekly changes in the average DM intake and CP intake estimates of the groups are presented in Table 1. Average $\mathrm{DM}$ and $\mathrm{CP}$ intakes of the kids, relative to metabolic BW, almost doubled from beginning to the end of the experiment in both groups.
There was no significant effect of kefir on BW and ADG during the study $(P=0.526$ and $P=0.530$, respectively). Average final BW of CON and KEF kids (as LSMEANS \pm SE) were $12.2 \pm 0.57$ and $11.8 \pm 0.57 \mathrm{~kg}$, respectively. The effect of experimental weeks on BW and ADG was significant $(P<0.0001)$, while no significant effect of gender or interactions was observed $(P>0.05)$. Overall average ADG of the groups were $107.6 \pm 14.34$ and $94.3 \pm 14.85 \mathrm{~g}$ /day for $\mathrm{CON}$ and KEF groups, respectively $(P>0.05)$. As shown in Fig. 2, ADG of both groups followed a quite similar pattern, characterized by a sharp decline 2 weeks after weaning and a prominent increase in the last 3 weeks.

All the kids were sub-clinically infected as confirmed by the presence of coccidial oocysts in their faeces. KEF had a lower frequency of OpG positive faecal samples than CON (Table 2; $P=0.043$ ). Kefir did not significantly affect maximum oocyst excretion of the kids or affect the age of highest oocyst excretion $(P>0.05)$. Overall average $\mathrm{OpG}$ of the groups were 4,361 $\pm 1,031$ and 2,813 $\pm 1,050$ for $\mathrm{CON}$ and $\mathrm{KEF}$ groups, respectively. KEF tended to have a lower level of Log-OpG when compared to CON $(P=0.074)$. Although there was a significant effect of sampling date $(P=0.006)$ on the Log-OpG, no significant interactions between effect of treatment and sampling date were observed $(P=0.219)$. Similarly, effect of gender as well as interactions, either between gender and treatment or between gender and sampling date, were not significant $(P>0.05)$. A triple significant interaction between effect of treatment, gender and sampling date was also absent $(P=0.446)$. As shown in Fig. 3, there was an increase in the Log-OpG values of both groups following weaning until the third week of the study and afterwards a decrease back to almost initial levels.

Frequency of animals showing diarrhea were similar $(P=$ 0.787 ) in both groups, with $7.62 \%$ of kids in $\mathrm{CON}$ and $6.50 \%$ of kids in KEF presenting with watery faeces (Table 2).
Fig. 1 Average daily feed (concentrate and alfalfa pellets) consumption of the experimental groups

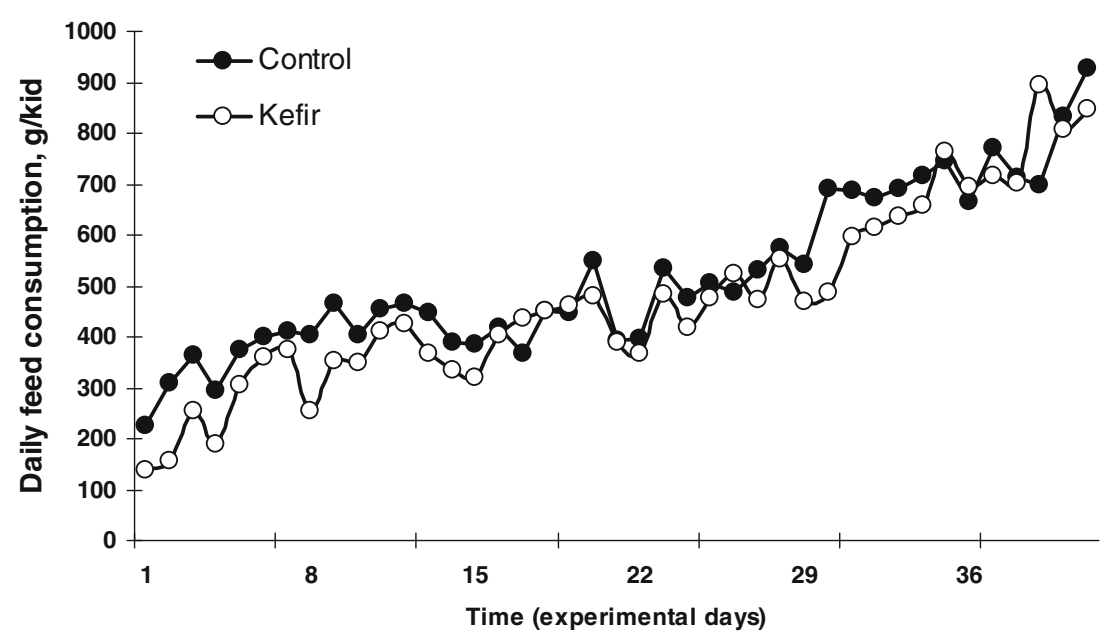


Table 1 Average dry matter (DM) and crude protein (CP) intake of the kids starting from weaning to 6 weeks after weaning

\begin{tabular}{llllll}
\hline \multirow{2}{*}{ Weeks } & \multicolumn{2}{l}{$\mathrm{DM}\left(\mathrm{g} / \mathrm{BW}^{0.75} /\right.$ day $)$} & & \multicolumn{2}{l}{$\mathrm{CP}\left(\mathrm{g} / \mathrm{BW}^{0.75} / \mathrm{day}\right)$} \\
\cline { 2 - 3 } \cline { 6 - 7 } & $\mathrm{CON}$ & $\mathrm{KEF}$ & & $\mathrm{CON}$ & $\mathrm{KEF}$ \\
\hline 1 & 57.04 & 43.39 & & 8.85 & 6.73 \\
2 & 68.28 & 57.90 & & 10.59 & 8.98 \\
3 & 64.12 & 66.10 & & 9.95 & 10.26 \\
4 & 75.03 & 72.65 & & 11.64 & 11.27 \\
5 & 96.47 & 89.22 & & 14.97 & 13.84 \\
6 & 102.63 & 106.33 & & 15.92 & 16.50 \\
\hline
\end{tabular}

$D M$ dry matter intake as proportion of metabolic weight $\left(\mathrm{BW}^{0.75}\right), C P$ crude protein intake as proportion of metabolic weight $\left(\mathrm{BW}^{0.75}\right)$

\section{Discussion}

Although kefir-fed kids had lower frequency of OpG positive samples and passed numerically lower (35\%) number of oocysts in their faeces, differences between the groups in Log-OpG did not reach a significant level $(P=0.074)$. This indicates that the numerical decrease in $\mathrm{OpG}$, which corresponded to a statistical tendency in lowering Log-OpG by kefir, was mainly due to lower frequency of OpG positive samples of KEF. As kefir did not affect the frequency of diarrhea, level of the highest oocyst excretion and age of kids at the highest oocyst excretion as wells as growth performance and feed consumption of the kids, overall effects of kefir do not have a significant impact on the sub-clinical infection.

Under farm conditions the vast majority of goats are subclinically infected with different Eimeria species (Koudela and Bokova 1998; Kusiluka et al. 1998; Değer et al. 2003; Gül 2007). Lambs reared under farm conditions have been shown to pass coccidia through their faeces within 2 weeks of life, confirming that newborns come into contact with the parasite within the first days of life (Le Sueur et al. 2009; Saratsis et al. 2011). In the present study, all kids shed oocysts, indicating that they all acquired sporulated oocysts from the contaminated environment and were sub-clinically infected. However, the presence of oocysts in faeces does not necessarily indicate a clinical state of infection. According to Scott (2007), coccidiosis is considered to be clinical in lambs when OpG is greater than 100,000 . None of the kids shed such a high number of oocysts during the 6-week post-weaning period, and probably thus, showed no clinical signs of infection. This is in agreement with other studies showing no clinical signs of infection, even if performance of the animals is impaired in the sub-clinically infected animals (Alzieu et al. 1999; Gauly et al. 2004; Reeg et al. 2005). Diarrhea is one of the most typical symptoms of the clinical state of coccidial infection. However, the frequency of kids showing diarrhea was also low and similar in both groups.

No difference was observed between the two groups for BW development. ADG of both KEF and $\mathrm{CON}$ were similar to previous reports with the same genotype under similar conditions (Ugur et al. 2004; Pala et al. 2005; Ataşoğlu et al. 2010). ADG of all kids decreased markedly until the third week of the study. During the same period (first 3 weeks), feed consumption and estimated nutrient intakes of the kids were not high enough to meet nutrient requirements when compared to the official recommendations of the NRC (1981). Thus the low nutrient intake level and the declining ADG of the kids in the first 3 weeks after weaning indicate a weaning shock due to undernutrition. There is a well-known relation between age of animals and decreased level of oocyst excretion due to acquired immunity against Eimeria species (Jalila et al. 1998; Kusiluka et al. 1998; Harper and Penzhorn 1999; Gauly et al.
Fig. 2 Average daily weight gain of the kids throughout the experimental weeks (Presented as LSMEANS and SE on error bars)

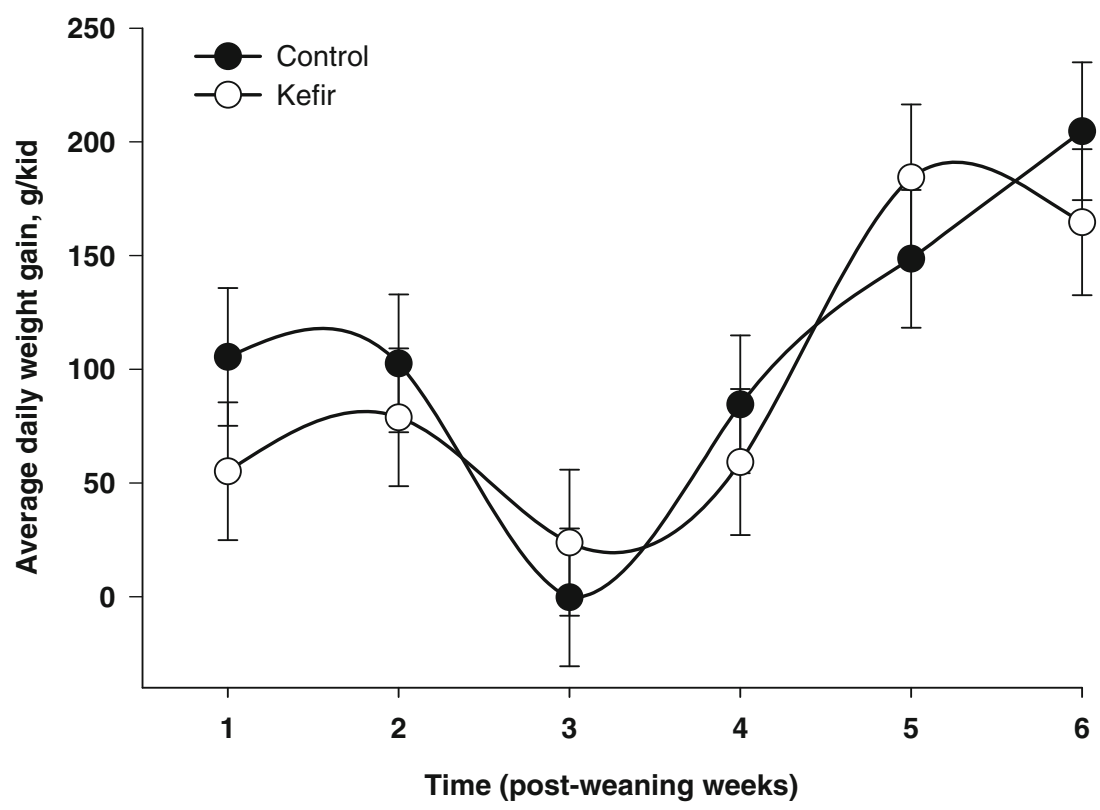


Table 2 Epidemiological parameters describing coccidial infection of the two groups

\begin{tabular}{|c|c|c|c|}
\hline & $\mathrm{CON}$ & KEF & $P$ value \\
\hline OpG positive samples $(\%)^{\mathrm{a}}$ & 86.6 & 77.8 & 0.043 \\
\hline Maximum $\mathrm{OpG}^{\mathrm{b}}$ & $24542 \pm 19097$ & $19397 \pm 18972$ & 0.553 \\
\hline Age at the highest $\mathrm{OpG}(\text { day })^{\mathrm{b}}$ & $61.3 \pm 10.14$ & $66.0 \pm 11.08$ & 0.336 \\
\hline Oocysts per gram of faeces $(\mathrm{OpG})^{\mathrm{c}}$ & $4361 \pm 1031$ & $2813 \pm 1050$ & - \\
\hline $\log -O p G^{d}$ & $2.78 \pm 0.190$ & $2.67 \pm 0.193$ & 0.074 \\
\hline Percentage of kids showing diarrhea $(\%)^{\mathrm{a}}$ & 7.6 & 6.5 & 0.787 \\
\hline
\end{tabular}

${ }^{\text {a }}$ Analyzed with Proc Genmod

${ }^{\mathrm{b}}$ Analyzed with one-way ANOVA, presented as means and SD

${ }^{\mathrm{c}}$ Un-transformed data, presented as LSMEANS and SE

${ }^{\mathrm{d}}$ Log-transformed data, presented as LSMEANS and SE

2004; Saratsis et al. 2011). Weaning is considered a stressful event that can, in some cases, precipitate clinical coccidiosis in kids (Imik et al. 2000). Although no clinical signs of infection were observed, oocyst excretion levels of both groups increased until the end of the third week. In comparison to protozoan infections including coccidiosis, effects of host animal nutrition on resistance to nematode infections are better known (Kyriazakis and Houdijk 2006). The increase in oocyst excretion might have been associated with undernutrition, since the initial level of oocyst excretion could only be approached within the last 2 weeks when feed consumptions of the kids were within the recommended limits.

The number of oocyst found in faeces is considered an indication of the number of intestinal cells destroyed by the intracellular residing Eimera species (Taylor et al. 2007) and therefore sub-clinical infections of coccidia must also be associated with some metabolic costs to the host animal. However, it is not known which level of sub-clinical infection, quantifiable by oocyst excretion, is associated with measurable effects on the performance of the host animal. The complexity in quantification of effects of infection on performance may arise from several factors, including composition of 16 Eimeria species that are known to infect goats with varying pathogenicity (Silva and Lima 1998; Harper and Penzhorn 1999). Kefir did not influence most of the infection parameters and performance of the kids; therefore, it is assumed that kefir might not have a significant effect on the composition of Eimeria species.

This study was performed under relatively high-hygienic conditions when compared to farm conditions in the field. As a consequence, the level of oocyst excretion of the kids was far lower in comparison to other studies (Koudela and Bokova 1998; Harper and Penzhorn 1999). Straw based litter material is considered as an ideal environment for oocyst survival and rapid sporulation (Berriatua et al. 1994; Saratsis et al. 2011). Regular litter removal from the growth units must, therefore,
Fig. 3 Changes in coccidial oocyst counts (Log-OpG) of the groups over 18 sampling dates over the 6-week period of the study (Presented as LSMEANS and SE on error bars)

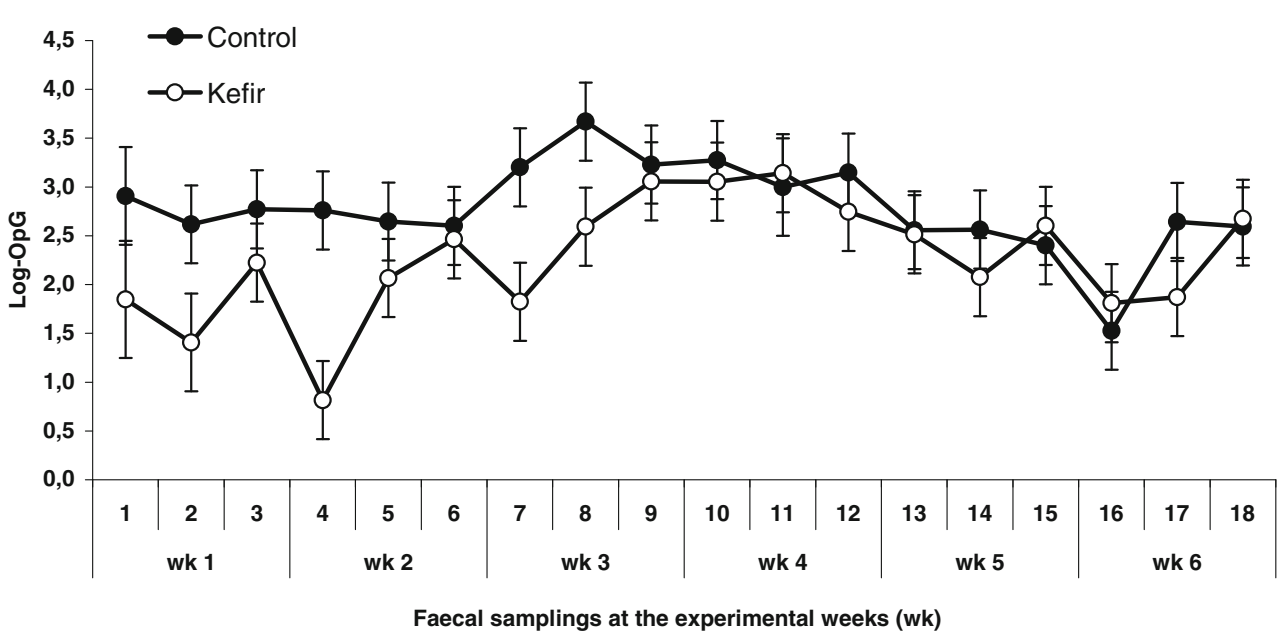


have limited coccidian re-infection, as different Eimeria species require up to 6 days for sporulation to reach infective stages (Taylor et al. 2007). Although KEF had a lower frequency of OpG positive samples, this effect was not associated with the performance, probably due to low levels of infection. It is generally accepted that probiotics exert their activity more influentially when husbandry conditions deviate from the optimum (Ataşoğlu et al. 2010). Thus, future studies may focus on effects of kefir on sub-clinical coccidial infection under worse farming conditions.

\section{Conclusion}

While KEF had a lower frequency of OpG positive faeces samples and tended to shed a lower number of oocysts by around one-third, the frequency of diarrhea, level of highest oocyst excretion, growth performance and feed consumption of the kids remained unaffected by kefir. Therefore it is concluded that overall effects of kefir do not have a significant impact on the sub-clinical infection and performance in weaned kids under relatively high-hygienic farming conditions.

Acknowledgements The authors thank Elif Arslan for technical assistance, Natasha Moroney for checking the language of the manuscript, and Altınkılıç Süt Ürünleri Company for supplying kefir.

Open Access This article is distributed under the terms of the Creative Commons Attribution Noncommercial License which permits any noncommercial use, distribution, and reproduction in any medium, provided the original author(s) and source are credited.

\section{References}

Alzieu, J.P., Mage, C., Maes, L., de Mûelenaere, C., 1999. Economic benefits of prophylaxis with diclazuril against subclinical coccidiosis in lambs reared indoors. Veterinary Record, 144, 442-444.

Ataşoğlu, C., Akbağ, H.I., Tölü, C., Daș, G., Savaș, T. and Yurtman, I.Y., 2010. Effects of kefir as a probiotic source on the performance of goat kids. South African Journal of Animal Science, 40, 363-370.

Berriatua, E., Green, L.E. and Morgan, K.L., 1994. A descriptive epidemiological study of coccidiosis in early lambing housed flocks. Veterinary Parasitology, 54, 337-351.

Dalloul, R.A., Hyun, S., Lillehoj, H.S., Tamim, N.T., Shellem, T.A. and Doerr, J.A., 2005. Induction of local protective immunity to Eimeria acervulina by a Lactobacillus-based probiotic. Comparative Immunology, Microbiology \& Infectious Diseases, 28, 351-361.

Daş, G., Tölü, C., Konyalı, A., Brka, M. and Savaș, T., 2005. Observations on the course of Eimerian oocysts output of naturally infected kids. Proceedings of the $18^{\text {th }}$ Scientific-Expert Conference of Agriculture and Food Industry, Neum, Bosnia and Herzegovina, 154-155.

Değer, S., Gül, A., Ayaz, E. and Biçek, K., 2003. The prevalence of Eimeria species in goats in Van. Turkish Journal of Veterinary \& Animal Sciences, 27, 439-442.

Donkin, E.F. and Boyazoglu, P.A., 2004. Diseases and mortality of goat kids in a South African milk goat herd. South African Journal of Animal Science, 34, 258-261.
Draksler, D., Mónica, L., González, S. and Oliver, G., 2002. The development of faecal flora in young Creole goats. Small Ruminant Research, 46, 67-70.

Gauly, M., Reeg, J., Bauer, C. and Erhardt, G., 2004. Influence of production systems in lams on the Eimeria oocyst output and weight gain. Small Ruminant Research, 55, 159-167.

Gül, A., 2007. The prevalence of Eimeria species in Goats in Iğdır. Turkish Journal of Veterinary \& Animal Sciences, 31, 411-414.

Harper, C.K. and Penzhorn, B.L., 1999. Occurrence and diversity of coccidia in indigenous, Saanen and crossbred goats in South Africa. Veterinary Parasitology, 82, 1-9.

Imik, H., Aytaç, H., Coşkun, B. and Fidanc1, H., 2000. Effects of E and $\mathrm{C}$ vitamins on the growth and immunity of the Angora goat kids exposed to stress. Turkish Journal of Veterinary \& Animal Sciences, $24,51-58$.

Jalila, A., Dorny, P., Sani, R. and Salim, N.B., Vercruysse, J., 1998. Coccidial infections of goats in Selangor, peninsular Malaysia. Veterinary Parasitology, 74, 165-172.

Koudela, B. and Bokova, A., 1998. Coccidiosis in goats in the Czech Republic. Veterinary Parasitology, 76, 261-267.

Kusiluka, L.F.M., Kambarage, D.M, Harrison, L.F.S., Daborn, C.J. and Matthewman, R.W., 1998. Prevalence and seasonal patterns of coccidial infections in goats in two ecoclimatic areas in Morogoro, Tanzania. Small Ruminant Research, 30, 85-91.

Kyriazakis, I. and Houdijk, J., 2006. Immunonutrition: nutritional control of parasites. Small Ruminant Research, 62, 79-82.

Le Sueur, C., Mage, C. and Mundt, H.C., 2009. Efficacy of toltrazuril (Baycox ${ }^{\circledR} 5 \%$ suspension) in natural infections with pathogenic Eimeria spp. in housed lambs. Parasitology Research, 104, 11571162

MAFF, 1986. Manual Veterinary Parasitological Laboratory Techniques, 3rd edition. Ministry of Agriculture, Fisheries and Food, London

Morand-Fehr, P., Richard, A., Tessier, J. and Hervieu, J., 2002. Effects of decoquinate on the growth and milk performance of young female goats. Small Ruminant Research, 45, 109-114.

NRC, National Research Council, 1981. Nutrient requirements of goats: Angora, dairy and meat goats in temperate and tropical countries. National Academy Press, Washington D.C

Orgeur, P., Mavric, N., Yvore, P., Bernard, S., Nowak, R., Schaal, B. and Levy, F., 1998. Artificial weaning in sheep: consequences on behavioural, hormonal and immuno-pathological indicators of welfare. Applied Animal Behaviour Science, 58, 87-103.

Ota, A., 1999. Protection against an infectious disease by enterohaemorrhagic E. coli $0-157$. Medical Hypotheses, 53, 87-88

Otles, S. and Cagindi, O., 2003. Kefir: a probiotic dairy composition, nutritional and therapeutic aspects. Pakistan Journal of Nutrition, 2, 54-59.

Pala, A., Savaş, T., Uğur, F. and Daş, G., 2005. Growth curves of Turkish Saanen goats' kids grouped for weight and body mass index. Archives of Animal Breeding, 48, 185-193.

Reeg, K.J., Gauly, M., Baurer, C., Mertens, C., Erhardt, G. and Zahner, H., 2005. Coccidial infections in housed lambs: oocyst excretion, antibody levels and genetic influences on the infection. Veterinary Parasitology, 127, 209-219.

Saratsis, A., Joachim, A., Alexandros, S. and Sotiraki, S., 2011. Lamb coccidiosis dynamics in different dairy production systems. Veterinary Parasitology, 181, 131-138.

SAS Institute Inc., 2010. SAS OnlineDoc ${ }^{\circledR}$ Version 9.1.3. Cary, NC, USA.

Scott, P.R., 2007. Sheep Medicine. Manson Publishing, London.

Silva, A.C. and Lima, J.D., 1998. Eimeria minasensis n. sp. (Apicomplexa: Eimeriidae) in the domestic goat Capra hircus, from Brazil. Memórias do Instituto Oswaldo Cruz, 93, 741-744

Stafford, K.J., West, D.M., Vermunt, J.J., Pomroy, W., Adlington, B.A. and Calder, S.M., 1994. The effect of repeated doses of toltrazuril on coccidial oocyst output and weight gain in suckling lambs. New Zealand Veterinary Journal, 42, 117-119. 
Stear, M.J., Doligalska, M. and Donskow-Schmelter, K., 2007. Alternatives to anthelmintics for the control of nematodes in livestock. Parasitology, 134, 139-151.

Taylor, M.A., Coop, R.,L. and Wall, R.L., 2007. Veterinary Parasitology, 3rd edn. Blackwell Publishing, Chicester

Ugur, F., Savas, T., Dosay, M., Karabayir, A. and Atasoglu, C., 2004. Growth and behavioral traits of Turkish Saanen kids weaned at 45 and 60 days. Small Ruminant Research, 52, 179-184.
Wang, C.R., Xiao, J.Y., Chen, A.H., Chen, J., Wang, Y., Gao, J.F. and Zhu, X.Q., 2010. Prevalence of coccidial infection in sheep and goats in northeastern China. Veterinary Parasitology, 174, 213-217.

Zhao, G.H., Lei, L., Shang, C., Gao, M., Zhao, Y.Q., Chen, C. and Chen, D., 2011. High prevalence of Eimeria infection in dairy goats in Shaanxi province, northwestern China. Tropical Animal Health and Production, in press: DOI 10.1007/s11250-011-9997-8. 